\title{
Importance of wnt-catenin signaling in hypertensive kidney diseases
}

\author{
Hajime Nagasu $^{1}$
}

Received: 3 July 2021 / Revised: 14 July 2021 / Accepted: 14 July 2021 / Published online: 26 August 2021

(C) The Japanese Society of Hypertension 2021

Wnt/ $\beta$-catenin signaling is a highly conserved pathway throughout evolution and plays important roles in a diverse array of biological processes, such as embryonic development, metabolism, and tumorigenesis. The regulation of $\mathrm{Wnt} / \beta$-catenin signaling is complicated. There are various ligands and receptors and many downstream effectors, including canonical and noncanonical pathways. The maintenance of intracytoplasmic $\beta$-catenin levels is under the tight control of a protein complex that includes glycogen synthetase kinase (GSK)-3 $\beta$. In canonical Wnt signaling, Wnt binds to the frizzled receptor that phosphorylates disheveled protein (Dsh/Dvl), which in turn phosphorylates and inactivates GSK-3 $\beta$. This triggers the translocation of catenin to the nucleus, where it acts as a coactivator for the transcription factors T-cell factor and lymphoid enhancer factor and drives the specific expression of target genes.

$\mathrm{Wnt} / \beta$-catenin signaling is activated in several types of cells in disease models. The $\mathrm{Wnt} / \beta$-catenin signaling pathway is activated in several pathobiological processes involved in tissue fibrosis $[1,2]$. The activation of $\mathrm{Wnt} / \beta$-catenin signaling induces cell cycle arrest in the G2/M phase, leading to the production of large quantities of growth factors, including tissue growth factor- $\beta$ and connective tissue growth factor [3]. Several studies have demonstrated how $\mathrm{Wnt} / \beta$-catenin signaling is regulated. In the presence of progressive renal injury, secretory Klotho expression decreases. As a result, $\mathrm{Wnt} / \beta$-catenin signaling increases, and fibrosis develops. Klotho protein overexpression attenuates $\mathrm{Wnt} / \beta$-catenin signaling in proximal tubular cells and the peritoneal membrane $[3,4]$, where it acts as a signal transduction factor that induces genes involved in cellular proliferation and differentiation, ultimately leading to tissue fibrosis.

Hajime Nagasu

hajimenagasu@kms-ndh.com

1 Department of Nephrology and Hypertension, Kawasaki Medical School, Okayama, Japan
Kasacka et al. aimed to understand the role of Wnt/ $\beta$-catenin signaling in hypertensive kidney disease. To this end, they determined the expression of $\mathrm{Wnt} / \beta$-catenin signaling in several hypertensive model rats. The basal levels of WNT4 and Fzd8 were higher in the cortex than in the medulla, but $\beta$-catenin expression was the same. This suggests that $\beta$-catenin might be regulated by different mechanisms in the cortex and the medulla. As several mechanisms are involved in the development or maintenance of hypertension, different hypertension models have different mechanisms of damage. For this reason, the authors investigated several hypertension models.

The renin-angiotensin system (RAS) plays an important role in not only maintaining blood pressure but also in causing hypertension. Hypertension can be divided into two types, depending on renin activity [5]. RAS either maintains or causes some or all of the high blood pressure in most patients. SHR and 2K1C hypertensive disease model rats, which were used in Kasacka et al.'s study, are high renin activity hypertension models. In these model rats, Wnt 4 and $\beta$-catenin expression in tubules was considerably higher than that in DOCA-salt rats, which are hypertension models with low renin activity. GSK-3 $\beta$ expression behaved differently in SHRs and DOCA-salt rats and was increased in tubules only of the latter. This suggests that the RAS might affect the activation of $\mathrm{Wnt} / \beta$-catenin signaling.

RAS-catenin interaction has recently been reported. Wnt/ $\beta$-catenin signaling and RAS activity have been found to be upregulated in aging kidneys [6], in which Klotho downregulation could affect catenin signaling. Furthermore, $\mathrm{Wnt} / \beta$-catenin is one of the regulators that control multiple RAS genes. On the other hand, Kasacka et al. found that the expression of catenin-related proteins was increased in RAS activation models, such as $2 \mathrm{~K} 1 \mathrm{C}$ and SHR. This suggests that RAS regulates catenin-related protein expression. Next, the authors considered the mechanism of these interactions between hypertension types and $\mathrm{Wnt} / \beta$-catenin signaling activation. They also discussed the role of oxidative stress because several studies have suggested that it is involved in the development of kidney damage [7]. Moreover, oxidative 


\section{Normal condition}

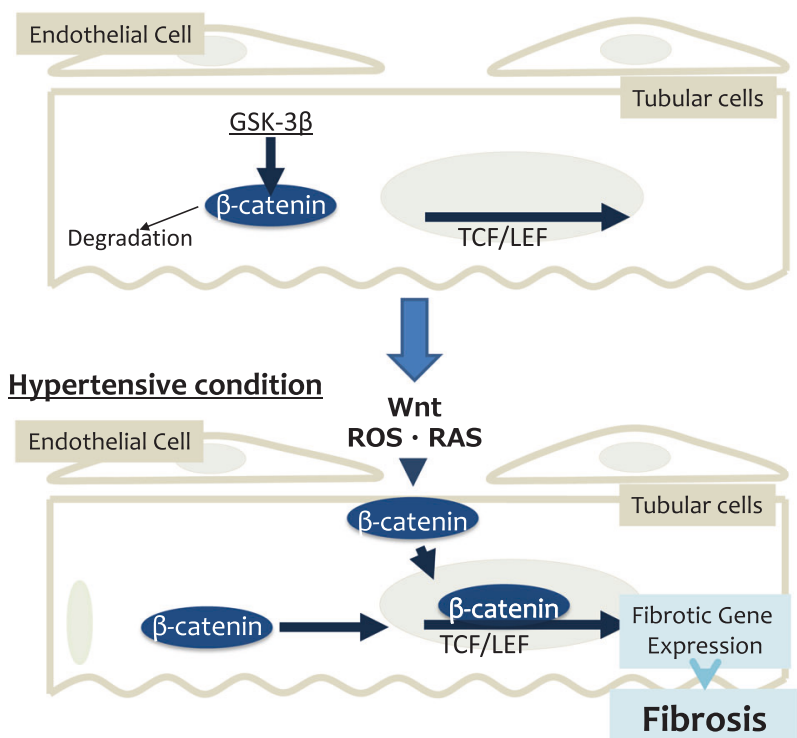

Fig. 1 The regulation and role of $\mathrm{Wnt} / \beta$-catenin signaling in kidney. Under normal conditions, $\beta$-catenin was degraded by GSK- $3 \beta$. Under hypertensive conditions, several factors activate $\mathrm{Wnt} / \beta$-catenin signaling, resulting in interstitial fibrosis. GSK-3 $\beta$ glycogen synthetase kinase (GSK)-3 $\beta$, ROS reactive oxygen species, RAS reninangiotensin system

stress affects Wnt $/ \beta$-catenin signaling. The binding of Dvl to the thioredoxin-like protein nucleoredoxin (NRX) depends on NRX activity, as the mutation of two catalytic cysteines disrupts Dvl binding. Furthermore, binding is inhibited by treatment with hydrogen peroxide, which suggests that the Dvl-NRX interaction is regulated by oxidative stress. Interestingly, NRX is a strong inhibitor of Wnt/ $\beta$-catenin signaling [8].

Recent research has suggested the importance of Wnt/ $\beta$-catenin signaling in kidney disease development, especially fibrotic changes (Fig. 1). Furthermore, it has been reported that cannabinoid receptor type 2 and $\beta$-catenin cooperate to promote renal fibrosis [9]. Wnt/ $\beta$-catenin signaling has also been found to play an important role in the development of glomerular sclerosis and tubulointerstitial lesions. Thus, research on the role of $\mathrm{Wnt} / \beta$-catenin signaling in chronic kidney disease is ongoing and is considered to be of great importance. Understanding Wnt/ $\beta$-catenin signaling is important for considering therapeutic targets, and further studies should be conducted based on the findings of Kasacka et al.'s study. Furthermore, the relationship between the RAS and $\mathrm{Wnt} / \beta$-catenin signaling is important for understanding the effectiveness of existing therapies. Therefore, it is imperative to uncover the underlying mechanism of $\beta$-catenin activation by the RAS.

\section{Compliance with ethical standards}

Conflict of interest The author declares no competing interests.

Publisher's note Springer Nature remains neutral with regard to jurisdictional claims in published maps and institutional affiliations.

\section{References}

1. Surendran K, Schiavi S, Hruska KA. Wnt-dependent beta-catenin signaling is activated after unilateral ureteral obstruction, and recombinant secreted frizzled-related protein 4 alters the progression of renal fibrosis. J Am Soc Nephrol. 2005;16:2373-84.

2. Kadoya H, Satoh M, Nagasu H, Sasaki T, Kashihara N. Deficiency of endothelial nitric oxide signaling pathway exacerbates peritoneal fibrosis in mice. Clin Exp Nephrol. 2015;19:567-75.

3. Satoh M, Nagasu H, Morita Y, Yamaguchi TP, Kanwar YS, Kashihara N. Klotho protects against mouse renal fibrosis by inhibiting Wnt signaling. Am J Physiol Ren Physiol. 2012;303: F1641-51.

4. Kadoya H, Satoh M, Nishi Y, Kondo M, Wada Y, Sogawa Y, et al. Klotho is a novel therapeutic target in peritoneal fibrosis via Wnt signaling inhibition. Nephrol Dial Transpl. 2020;35:773-81.

5. Laragh JH, Letcher RL, Pickering TG. Renin profiling for diagnosis and treatment of hypertension. JAMA. 1979;241:151-6.

6. Miao J, Liu J, Niu J, Zhang Y, Shen W, Luo C, et al. Wnt/betacatenin/RAS signaling mediates age-related renal fibrosis and is associated with mitochondrial dysfunction. Aging Cell. 2019;18: e13004.

7. Nagasu H, Satoh M, Kiyokage E, Kidokoro K, Toida K, Channon $\mathrm{KM}$, et al. Activation of endothelial $\mathrm{NAD}(\mathrm{P}) \mathrm{H}$ oxidase accelerates early glomerular injury in diabetic mice. Lab Invest. 2016;96:25-36.

8. Funato $\mathrm{Y}$, Michiue T, Asashima M, Miki H. The thioredoxinrelated redox-regulating protein nucleoredoxin inhibits Wnt-betacatenin signaling through dishevelled. Nat Cell Biol. 2006;8:501-8.

9. Zhou S, Wu Q, Lin X, Ling X, Miao J, Liu X, et al. Cannabinoid receptor type 2 promotes kidney fibrosis through orchestrating betacatenin signaling. Kidney Int. 2021;99:364-81. 